\title{
Violência e Sofrimento Social: a resistência feminina na obra de Veena Das'
}

\section{Violence and Social Suffering: women's resistance in Veena}

\section{Das' works'}

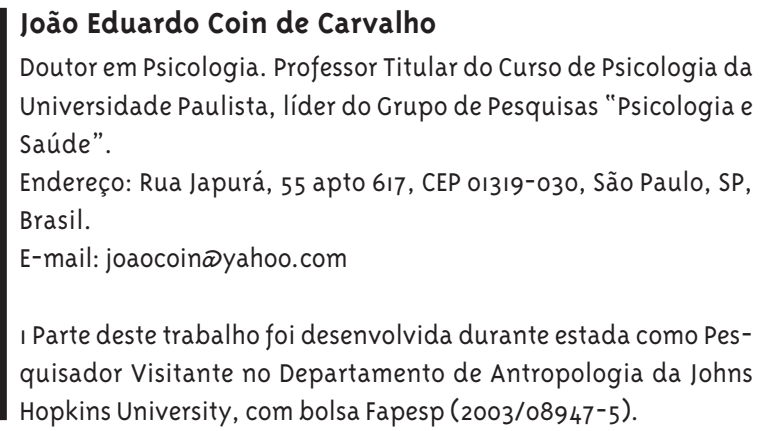

Resumo

O sofrimento social vem sendo discutido por pesquisadores brasileiros em diferentes contextos, normalmente associado às populações socialmente excluídas, vítimas de violência e da miséria crônica, com atenção especial para sua repercussão nos corpos de mulheres e crianças. Neste trabalho discute-se o conceito de sofrimento social, que tem como referência a Antropologia Médica a partir dos trabalhos da antropóloga indiana Veena Das, buscando diálogo com questões de gênero e saúde em nosso meio. A importância dessas concepções é investigada nos trabalhos de Das sobre a resistência do feminino no imaginário e no cotidiano, nos quais esta resistência aos discursos hegemônicos em meio à violência e ao sofrimento social se apresenta de maneira sutil nos usos cotidianos dos corpos. Concluindo, a posição sobre a resistência feminina na perspectiva de Veena Das pode ser útil para estudos e intervenções no campo da saúde, realizados com mulheres brasileiras de populações em situação de miséria crônica em contextos de sofrimento e exclusão social. A escuta de mulheres jovens e pobres a respeito da maneira como (não) dirigem seus destinos e elaboram projetos de vida, aponta para a possibilidade de investigar fenômenos que remetem aos mesmos cenários descritos por Das. A busca de sua inserção em movimentos imaginários que se materializam em suas falas e nos usos e cuidados com seus corpos pode ser decisiva para, em contextos de promoção de saúde, dar entendimento e intervir sobre processos que parecem sem sentido, mas que guardam na sua incompletude e incerteza a marca indelével do humano.

Palavras-chave: Sofrimento social; Violência; Veena Das; Imaginário; Gênero. 


\section{Abstract}

Social suffering has been studied in several circumstances by Brazilian researchers, usually associated with socially excluded people who are victims of violence and chronic poverty. Special attention has been given to its effects on women's and children's bodies. In this work, we deal with the Medical Anthropology concept of social suffering, especially from the works of the Indian anthropologist Veena Das, searching for a dialogue between social suffering, health, and gender questions. Her conceptions about mental imagery and women's daily resistance to hegemonic discourses under violence and social suffering support a new perspective on women's body use and care. We conclude that such modality of women's resistance in Veena Das' view can be useful to conduct studies and social interventions concerning Brazilian women submitted to suffering and inequality. Listening to young and poor Brazilian women speak about the way they can (not) control their destiny and define life projects could offer clues to intervene in health promotion contexts. Under imaginary movements that lead to language use and body care, these practices could bring meaning to social processes that have uncertainty and incompleteness as human marks.

Keywords: Social Suffering; Violence; Veena Das; Mental Imagery; Gender.
O sofrimento social é tema que vem sendo discutido por pesquisadores brasileiros em diferentes contextos, normalmente associando esta condição às populações socialmente excluídas vítimas de violência, seja esta originada no Estado ou mesmo na família, com atenção especial para sua repercussão nos lugares sociais e nos corpos desses grupos. Para Gonçalves Filho (1998), que alinhava marxismo e psicanálise em um estudo incisivo sobre a condição subjetiva e social de populações excluídas, este é o caso da humilhação social associada à pobreza e à opressão que a instala nos corpos e nas subjetividades dos "cidadãos impedidos". Sawaia (1999) fala de sofrimento ético-político ao tratar daquilo que mutila a vida (corpo e alma) agregando o desejo, a temporalidade e a afetividade junto ao poder, à economia e aos direitos sociais, na soma que determina a exclusão social. Esse também é o caso de Carreteiro (2003), que usa o termo sofrimento social para discutir a humilhação e a vergonha de indivíduos sujeitos a processos de desfiliação social e que respondem a essa condição com seus próprios corpos. Tais autores têm demonstrado também preocupação com as dimensões metodológicas de suas investigações, nas quais a condição de ativista se sobrepõe, muitas vezes, à de pesquisador.

O ponto de partida deste trabalho é a discussão sobre o conceito de sofrimento social, englobando não apenas sua dimensão teórica, mas também aquela que conduz à intervenção e transformação da realidade, como indicada nos trabalhos de Arthur Kleinman e Veena Das, tendo como referência o campo da Antropologia Médica. No caso desses autores, o sofrimento social é discutido em situações sociais e políticas comparáveis às que vêm sendo descritas pelos pesquisadores brasileiros no contexto da violência, da miséria crônica e da exclusão social, o que possibilitaria especialmente um diálogo com questões de gênero e saúde.

Para Kleinman e colaboradores (1997), o sofrimento social congrega uma grande variedade de experiências de dor, trauma e distúrbios - na fome, na violência doméstica, no stress pós-traumático, na doença crônica, ou nas doenças sexualmente transmissíveis que envolvem, simultaneamente, situações de saúde, bemestar, justiça, moralidade e religião. Nesse sentido, o que melhor caracteriza o sofrimento social é sua compreensão não como problema médico ou psicológico, o que reforçaria sua dimensão individual, mas como uma 
experiência social (1997). Suas raízes estão, desta forma, intimamente ligadas aos processos sócio-políticos nos quais podem ser encontradas a violência e a opressão, o que não restringe esse sofrimento às populações dos países pobres do $3^{\circ}$ mundo, mas também pode ser encontrado nas "margens" dos países ricos, como nas downtown de grandes cidades americanas como Nova York, Chicago e Baltimore, ou nos subúrbios de Paris e Londres. Presentes em meio às questões de infância e gênero, estes estudos sobre sofrimento social contemplam ainda expressões de uma modalidade de resistência que se faz pela forma como estas populações dispõem da linguagem e de seus corpos (Kleinman e Kleinman, 1994).

Ao lado das preocupações com a conceituação desses fenômenos, vale destacar que do ponto de vista metodológico esses autores têm buscado recursos para práticas de intervenção e de transformação de realidades sociais, ocupando geralmente o papel de participantes ativos nos cenários de investigação, não apenas como "provedores de saúde", mas defendendo os direitos e contribuindo como ativistas (advocates) das causas das populações sujeitas à condição de sofrimento social (Das, 1996). Esse posicionamento tem inspirado e determinado muitas e diversas ações de pesquisa e intervenção social, com atenção especial para a área de saúde (Biehl e Eskerod, 2005; Petryna e col., 2006).

Sob a perspectiva de uma abordagem qualitativa e interdisciplinar, os estudos sobre sofrimento social apresentam o discurso, na tradição foucaultiana, como conceito necessário para compreender esses fenômenos. Por outro lado, a filosofia da linguagem será um dos guias utilizados, especialmente por Veena Das, para construir este cenário epistemológico e metodológico onde estão os estudos sobre sofrimento social, associando-o a um certo uso do corpo em situações onde a linguagem, paradoxalmente, parece "falhar".

Em vários de seus textos, a antropóloga indiana Veena Das (1990, 1996, 1997, 2000, 2006) trata da violência social que é incorporada no dia-a-dia. Nesses trabalhos ela não tem considerado uma violência qualquer, mas aquela que provoca um ponto de inflexão tanto na vida daqueles que a sofreram diretamente, quanto na daqueles que são histórica e imaginariamente alcançados por ela. Das chama de eventos críticos (critical events) a estas circunstâncias provocadoras, caracterizados pela brutalidade de instituições como a família, o Estado ou grupos religiosos ou econômicos, como indústrias químicas e farmacêuticas que mantém suas plantas industriais e centros de pesquisa em países pobres da América Latina, da África e da Ásia. Depois de submetidos a eventos críticos, os atores sociais assumem novas formas, inclusive de expressão, inscrevendo nos seus próprios corpos aqueles acontecimentos, quando as palavras falham e o corpo é o único meio de expressão (Das, 1996).

Ao invés de considerar a violência como um fenômeno social cujas causas são distantes e indefinidas ou localizando-a no domínio do sujeito e da patologia, Das persegue os efeitos que certos eventos críticos promovem nos discursos e nos corpos daqueles que são, habitualmente, os principais e os primeiros receptáculos da violência do Estado e da família: crianças e mulheres. Nos trabalhos aqui referidos, Das tem como alvo, mais especialmente, mulheres, mesmo aquelas que não sofreram na sua própria pele a violência de uma experiência social disruptiva, mas que ainda assim mantêm o seu registro, manejando o uso de seus corpos no cotidiano.

Para entender o sentido proposto por Das para a experiência das mulheres submetidas a eventos críticos, com a instituição de novas possibilidades subjetivas em meio à fratura social e familiar provocada por estas circunstâncias, é preciso recuperar, mesmo que brevemente, aquilo que ela sugere garantir sua existência subjetiva e social, o que Das $(1997,1998)$ vai buscar em suas leituras de Wittgenstein amparadas nas contribuições do filósofo americano Stanley Cavell (1999).

\section{Cotidiano e Dor}

Algumas formas de violência não podem ser compreendidas. Esta violência que não pode ser reconhecida como humana, que coloca em jogo o próprio status de humano daquele que a perpetra, fica sem palavras. 0 que acontece com esta violência, com a memória desta violência? Como esta violência pode ser recuperada e como ela atua sobre os sujeitos, construindo um lugar para ser habitado?

Das toma a separação entre Índia e Paquistão como exemplar de evento social produtor de uma enorme violência social. Cerca de cem mil mulheres de ambos os lados foram seqüestradas e violentadas. A exemplo dos eventos que se deram após a divisão da antiga 
Iugoslávia, chama a atenção como esta violência se deu não somente entre desconhecidos, mas também entre vizinhos e mesmo dentro das próprias famílias, conduzindo pessoas comuns a atos que desafiam a crença na humanidade e na civilização e que tiveram nas mulheres de ambos os lados (hindus e muçulmanas) seu alvo prioritário.

Em Language and Body, Das elabora o cenário vivo, imerso em linguagem, onde se conectam voz e cultura, pelo qual ela pretende que se poderá apreender aquela violência e seus efeitos sobre self, comunidade e nação. Para ela, a chave que poderá dar conta desses eventos e, então, recuperá-los, dar-lhes sentido, está no imaginário. Atravessando concepções teóricas bastante distintas, Das apela para autores que lidam com este registro, o imaginário, para poder apreender uma realidade (in) humana que aparentemente tem lugar no intervalo entre a fantasia e o real - mas que nem por isso é menos efetiva. E entre estes autores que "responderam ao chamado do mundo no registro do imaginário" (Das, 1997, p. 69), como o psicanalista Jacques Lacan, o filósofo Cornelius Castoriadis e os escritores-filósofos indianos Tagore e Manto, ela reconhece também o filósofo da linguagem Ludwig Wittgenstein.

Com Wittgenstein, Das afirma que a compreensão e o reconhecimento da dor - a própria dor - não se constitui numa circunstância apenas individual, apoiada no mundo interior de um sujeito, mas depende de uma certa gramática. Para ilustrar esse entendimento, ela recorre aos Blue and Brown Books, onde Wittgenstein considera que na afirmação eu tenho dor, o autor da frase procura escapar a algo que não pode ser expresso. Para ele, isso que se parece com uma declaração indicativa de algo que se passa internamente é de fato o início de um jogo de linguagem. É um pedido de reconhecimento sobre algo que se passa entre o autor e quem o escuta. Assim, esta falta que tem a linguagem para representar a linguagem compreendida com um meio universal (Hintikka e Hintikka, 1989), solicita que no jogo se vá buscar o sentido mesmo para aquilo que nos parece privado - e que tem o mesmo estatuto do que nos é exterior, público.
Seguindo esse entendimento, é notável nos textos de Das sua preocupação em buscar sentido naquilo que não tem sentido, mas que nós insistimos em chamar de humano. Assim, esta humanidade do comportamento associado, por exemplo, à violência extrema, não deveria ser buscada apenas no indivíduo que conduz essa violência, mas nas próprias situações do cotidiano que aquele e outros indivíduos estão experienciando. Essa experiência, ela insiste, não deve ser compreendida como algo interior - sem negar que o interior também ofereça uma experiência - mas nos efeitos da linguagem, mais ainda, da gramática da linguagem, nas falas e nos comportamentos humanos.

É possível dizer, nesta direção, que aquilo que se faz, o comportamento, está presente na linguagem como possibilidade e não é estranho a ela. Mas e a violência extrema, aquilo que não parece humano, que não tem palavras para ser descrito? A qual gramática refere? Onde buscar sentido para esses eventos? Para Das, esse sentido irá ser buscado também no cotidiano, num conhecimento que está ali mas só pode ser evocado, e isto através de meios que não seriam apenas linguageiros. Eles são evocados e referidos através de imagens e de recursos estéticos que se constroem pela linguagem e também com o próprio corpo. Identificando o cotidiano como o lugar da recuperação daqueles sentidos, Das o carrega de uma certa magia, perfazendo uma idealização que não exclui o embate: ela converte o cotidiano físico de Wittgenstein num outro, encarnado, feito de pessoas, afetos e conflito. O mesmo cotidiano que, como entendo, contém e sustentará a prática do cientista social. ${ }^{2}$

A instalação da violência no cotidiano como efeito das condições sociais se dá de maneira dramática e espetacular, como nas ações que acompanhamos nos noticiários que chocam e provocam horror - embora também pareçam nos atrair - mas também está no cotidiano, nos pequenos gestos, nas escolhas despreocupadas e naquilo que direciona os nossos olhares. A violência e a exclusão, seus efeitos como o sofrimento social e as reações que elas suscitam não podem ser compreendidos, neste entendimento, como práticas individuais, mas compartilhadas através da imersão

\footnotetext{
2 Este entendimento sobre a violência extrema e não-humana, como efeito das relações sociais, pode ser facilmente inserido nas discussões que vêm sistematicamente assombrando a realidade brasileira quanto à diminuição da maioridade penal e a necessidade de culpabilização individual, afastando os componentes históricos e imaginários que sustentam esta violência e sua "falta de sentido".
} 
no mesmo cenário de linguagem e de possibilidades instituído pelo imaginário social.

O cotidiano encarnado não está fora da linguagem, está imerso na linguagem, ou ainda, está colado nela. A gramática da linguagem é assim instalada a partir desta interface entre linguagem e cotidiano. Dessa forma, é preciso entender que as ações sobre o mundo desempenhadas pelos indivíduos e pelos grupos, nos casos, por exemplo, da violência extrema, não podem ser compreendidas como possuindo um agente. Em outras palavras, linguagem e comportamento têm por suporte uma gramática que independe de um cálculo (Kusch, 1989) por parte de indivíduos que não "sabem" o que fazem.

Em suma, o que Das afirma, seguindo Wittgenstein, é que a violência que não tem lugar nas palavras e que não pode ser tratada ali só poderá, por outro lado, ser retomada e literalmente tratada no cotidiano. Mas essa aposta no cotidiano não pretende indicar que há alguém que resiste no cotidiano, pois não há, necessariamente e sempre, este agente da resistência: ao menos não se deve falar de uma resistência calculada; mas de uma existência possível. Isso não significa que não existam sujeitos que interfiram na realidade, e que se trate de uma pura submissão aos jogos de linguagem. $\mathrm{O}$ agenciamento se faz de maneira indireta, transversal, e mesmo através de outros indivíduos que não pertencem imediatamente àquele evento crítico. Por exemplo, cientistas sociais e ativistas.

A defesa do sentido como envolvendo algo que não se dá "dentro" ou "fora" do sujeito, nem como estrutura nem como experiência (interna), mas como em encontros e relacionamentos, indica a associação de Das com Wittgenstein sobre um entendimento da linguagem como não possuindo um papel representacional, mas como meio no qual estamos imersos. Nessa direção, ela reconhece a importância do gesto e do movimento - do imaginário - para esta cena na qual está a linguagem, ou ainda a fala. A presença e a importância do cotidiano na elaboração de novas formas de subjetividade provocadas pela perturbação de um evento crítico podem ser localizadas na obra de Das através de um exemplo de sua etnografia, onde ela faz um deslocamento do discurso da resistência do feminino, que tem como emblema a figura de Antígona, a mulher que resiste à chamada da lei através de uma voz dramática, espetacular, para Asha, uma indiana invisível cuja resistência se faz no dia-a-dia (Das, 200o).

\section{Asha: gênero, performance e invisibilidade}

Usando de um estilo único, literário, Das constrói, a partir de sua etnografia, "quase-personagens" que virão sustentar suas teses. A estratégia parece ser a de trazer uma experiência concreta e visível para a discussão, neste caso, sobre o sofrimento. Materializar na história e no corpo o sofrimento faz seu argumento ganhar força na medida em que se afasta de uma abstração e se apóia em carne e discurso. Assim, surge Asha (Das, 1995, 2000). De uma família de Punjabi, perde o marido muito jovem, vítima de uma doença que o consome em algumas semanas. Sob a tragédia pessoal, e sem filhos, ela continua vivendo com a família do marido. Nessa cultura, não é incomum se fazer a inclusão de uma mulher jovem e viúva através da "cessão" de uma criança do círculo familiar - um sobrinho, por exemplo - para ser seu filho. Isto é, a família na qual ela está incluída oferece um filho para uma adoção virtual, o que significa que, ao ficar adulto, esse filho deverá zelar também pela mãe adotiva. É o que acontece aqui, quando a cunhada com quem Asha vive oferece seu próprio filho para ser "compartilhado". Essa é uma forma de suprir a necessidade de ser mãe, vista como parte da natureza humana e feminina; mas é também, segundo Das, uma forma de substituir ou ocupar esta jovem mulher com as questões da maternidade, ao invés de deixá-la a mercê de sua sexualidade, marcando uma diferença importante entre estas duas experiências: sexualidade e maternidade.

Na mesma direção desse controle sobre o corpo feminino, Das indica como a convivência de Asha com a família conduz a que ela carregue sinais em seu próprio corpo que digam do lugar que ela, como uma jovem viúva, ocupa. Assim, para que esse lugar da mulher seja expressamente visível, ela deve atuar uma contínua performance:

“O rosto de Asha, como o de uma viúva, deve sempre possuir a presença do luto - a separação de seu cabelo sem a marca do vermelho, ela dizia, era simbólica de tudo que deve ser evitado no cosmos. A performance da identidade feminina da viuvez tinha a força de um ritual social compulsório. [...] Sua face e seu corpo devem constantemente atuar esta estética." (Das, 200o, p. 214) 
Esse seria seu destino, caso não houvesse o Partition, a guerra civil deflagrada no processo de independência da Inglaterra e que produz a separação entre Índia e Paquistão, colocando de lados opostos hindus e muçulmanos. Entre os embates que seguem este evento e que produzem violência e mortes, desenrola-se uma tragédia familiar, com a morte de uma das cunhadas de Asha - aquela com quem ela compartilhava a maternidade - e a dispersão da família. Nesse momento, Asha vai se abrigar na casa de seus pais, junto com o filho "adotivo", e sofre com a desconfiança da família que vê seu retorno como um peso - mais gente para sustentar num contexto de extrema dificuldade - que se alia às fantasias quanto às suas pretensões em relação à herança paterna.

Sem lugar, ela retorna ao convívio da família do marido. Viúva e jovem, começa a ser sexualmente assediada pelo cunhado, agora também viúvo. Temendo ceder a estas investidas, e na possibilidade de enfrentar a desonra da família com a manutenção de um relacionamento com o cunhado, Asha busca sua própria desonra, dentro desse contexto familiar e social, num novo casamento fora da família, quebrando um importante tabu. Numa atitude subversiva, "impensável”, responde com seu próprio corpo à sexualidade e à maternidade que a família manejava controlar. Condenada ao desaparecimento da cena familiar durante os oito anos seguintes, após esse período de exílio ela volta a se aproximar da família, com a ajuda da irmã mais nova do primeiro marido, através de um trabalho de reconstrução paciente, e feito no cotidiano, das ligações que haviam desmoronado a partir do Partition.

A história, recuperada por Das ao longo de várias entrevistas, procura ilustrar a maneira através da qual a violência do Partition alcançou uma mulher que sequer fora diretamente afetada pelos conflitos entre muçulmanos e hindus, e que resultaram em estupros, assassinatos, suicídios e seqüestros de milhares de mulheres de ambos os lados. Muitas tiveram seus próprios corpos, especialmente os genitais, marcados com palavras de ordem nacionalista (victory to India; long live Pakistan; this thing is ours). Enquanto os homens mortos nesses conflitos foram transformados em heróis nacionais, o destino de tantas mulheres, vítimas também de suas próprias famílias, levadas a suportar a dor da (in)existência em silêncio, denuncia a reificação do lugar ocupado por mulheres que, em vista de uma situ- ação limite, são mortas pelo inimigo, caladas pelos próprios familiares e violentadas por ambos. Um sofrimento que marcou não apenas seus corpos, mas também o imaginário no qual mulheres como Asha irão se mover.

A história de Asha revela um discurso que não contém apenas palavras, mas se materializa também através de performances nas quais os corpos femininos, os mesmos marcados por tatuagens nacionalistas, mostravam que havia algo mais a ser dito e sob outra forma de expressão. Essa modalidade de expressão está presente na maneira como, por exemplo, o incômodo de ser um peso para o irmão é relatado por Asha. Segundo Das: "isto nunca teria sido dito diretamente por eles, mas tinha sido comunicado através de um discurso velado e numa estética de gestos". A fala assim continha "palavras não ditas, gestos performáticos, e todo um repertório de noções culturalmente densas que envolviam estas falas" (Das, 2000, p. 211). Sentidos construídos a partir do mundo vivido. Mas é na sua ação de recuperar no cotidiano as ligações perdidas e o lugar que lhe caberia como mulher que esta performance ganha nova importância, como uma intervenção sobre sentidos que não se constroem alternativamente no sujeito ou no ambiente social.

A pergunta que Das tenta responder nesses textos - Como a violência do Partition se instalou nas relações cotidianas? - vai buscar resposta não na memória daqueles acontecimentos, mas na sua incorporação no imaginário enquanto linguagem, gesto e movimento no cotidiano.

A história de Asha ilustra uma situação na qual lei e transgressão estão juntas. Não se trata de antes a lei e depois a transgressão, mas de como essas duas possibilidades dividem e convivem em Asha. Algo de que ela não pode escapar. Para lidar com essa condição provocada pelo Partition, ela se dirige para o cotidiano, o que significa responder com seu corpo, ao invés de buscar um plano mais alto. Das toma esta mulher como falando de seu processo de reocupação dos signos que a feriram e marcaram e que instituem a continuidade entre a tragédia e a vida cotidiana. Se os relacionamentos são brutalmente afetados por determinadas circunstâncias sociais, então "o passado encontra o presente não necessariamente como uma memória traumática, mas como um conhecimento envenenado”, que só poderá ser alcançado através de um conhecer por sofrer (Das, 200o, p. 221). 
A incorporação daqueles eventos e a submissão dos corpos e das vontades a desígnios familiares e sociais não se dá perfeita e completamente. A nova situação produzida pelo Partition irá ser tomada por mulheres como Asha enquanto também geradora de novos entendimentos sobre seus lugares com novas possibilidades de ocupação do mundo. A passividade feminina seria, assim, apenas aparente. A repossessão da subjetividade feminina vai ser compreendida, como também entendo, pela incorporação de um discurso sobre a mulher, um discurso familiar e religioso - e eventualmente do Estado - que não se transforma puramente em destino, mas se articula com outros discursos, cuja dimensão imaginária se faz no cotidiano:

“Nesta direção, a questão de como alguém faz seu próprio mundo precisou ser recolocada para ela, de tal forma que ela se movimentou entre diferentes caminhos pelos quais poderia encontrar o sentido para recriar seus relacionamentos em face de um conhecimento envenenado que havia sido derramado sobre ela" (Das, 200o, p. 211).

O estrago produzido pelo Partition oferece também para Asha uma nova possibilidade de ocupação de seu próprio corpo. Segundo Das, ela tem seu corpo incorporado ao corpo do marido morto, ela deve ser assim, como deve ser também reconhecida como alguém cuja sexualidade e maternidade foram controladas. 0 turbilhão que segue o Partition perturba o lugar que Asha ocupa de tal forma que ela, então, poderá se mover na fratura aberta pelo Partition, que detona uma situação na qual a sexualidade e a maternidade podem ser reconhecidas - causando desaprovação.

O Partition, como evento crítico, produz uma situação que dispõe de novos projetos, a ocupação de novos lugares por mulheres como Asha. Confrontada com um não-lugar, um lugar de falta, insuportável para ela, seu movimento é de fuga para uma nova relação que dê conta de sua sexualidade, de um novo lugar como mulher que contemple a possibilidade de ser mãe. Para Das, a história de Asha em relação ao "preenchimento" de sua maternidade aponta a construção de um self feminino que está de acordo com os paradigmas culturais dominantes (Das, 200o, p. 210), que definem a maternidade como o lugar para o investimento do desejo, no lugar da sexualidade, por exemplo. Mas mudanças no contexto social levaram a uma alteração nas "necessidades" femininas como definidas por elas mesmas e pelos outros atores sociais. Dessa forma, Asha constrói um lugar diferente sobre a maternidade, guardando aquilo que se esperava dela dentro das tradições de seu grupo, mas oferecendo um novo significado para a possibilidade de ser mãe, através de um arranjo que foi sendo construído pacientemente no dia-a-dia - o de ser mãe dentro daquele grupo sem ter um filho biológico ali.

Para Das, Asha irá realmente conhecer através da paixão (sofrimento) e se coloca numa posição subjetiva que está na encruzilhada de três lugares: transgressor, vítima e testemunha. O Partition produz uma intensa identificação com um determinado grupo religioso/ étnico por um lado, mas por outro causa uma importante degradação das relações afetivas mais íntimas. As novas possibilidades relacionais proporcionadas pelo Partition conduzem a escolhas que fragmentam o sujeito e que irão, nesse caso, solicitar um trabalho de recuperação do tecido familiar através de um conhecimento que não é intelectual, mas é paixão e é conduzido pelo trabalho de mulheres.

As metáforas de poder/aprisionamento de corpo pela alma - ou vice-versa - não dão conta deste complexo e delicado trabalho de auto-criação. Dessa forma, interior e exterior, assim como corpo e alma, devem ser entendidos como tendo uma relação na qual eles estão próximos e ligados, como a lei e a transgressão estão ligadas. A violência do Partition solicita que Asha pense em uma nova forma de habitar o mundo, na qual ela deve trafegar entre o permitido e o proibido, ressignificando o passado através de novas narrativas, mas também através de atos no mundo sobre os vínculos, "reparando relações e dando reconhecimento para aqueles indivíduos que as normas oficiais têm condenado" (Das, 200o, p. 223).

Essa ação "subversiva" não implica, assim, em ruptura, mas na elaboração do que compreendo ser uma nova cena, uma imagem social diferente que permite acomodar aqueles mesmos atores sociais e seus afetos. Uma ação efetiva sobre o imaginário que contém todos esses elementos.

Tomando a etnografia na qual Asha é a protagonista, Das é mais do que alguém que apenas descreve, ela oferece seu corpo e sua escrita para fazer a presença de Asha no cotidiano, fazendo da história dessa mulher única um guia para os processos sociais que atra- 
vessaram toda sua comunidade e que materializaram uma condição que contempla o alvo da violência e, simultaneamente, a instituição de novas possibilidades de ser mulher. É no reconhecimento desses novos lugares e no manejo do imaginário que suporta a possibilidade de instituir diferentes posições para mulheres e mães que toma a frente a presença e importância do cientista social. Defendendo explicitamente o papel do pesquisador social como o de um interventor na realidade (advocate), em seus textos Das afirma que, mesmo que não se possa apropriar da dor do outro - ou do que acontece com o outro - eu posso emprestar meu corpo - ou minha escrita - para que essa dor possa acontecer comigo, o que está, no âmbito da dor, dentro de sua gramática. Essa ação irá permitir, assim, que aquela existência possa se dar também através do cientista social, de seu texto, e de sua ação, materializando um ato que se dá, como entendo, ainda que politicamente comprometido e metodologicamente suportado, sob o domínio do imaginário: isto é, incerto e incalculável, mas mesmo assim podendo ser efetivo, reconstruindo relações, desafiando as fraturas do social.

Apoiada em Wittgenstein, Veena Das não deixa de ser mulher, antropóloga e indiana. E é nesse sentido que ela irá ancorar a discussão proposta pelo filósofo num porto que é o de um cotidiano encarnado, experienciado, vivido. Indicar a importância da linguagem não significa estabelecer a precedência da linguagem, mas mostrar como a linguagem institui e é instituída também pelo cotidiano. O sofrimento e a descrença, que, como Das sugere, estão no texto de Wittgenstein, vão ser atualizados no seu discurso de antropóloga e mulher, materializando uma discussão que, sem esse substrato encarnado num cotidiano empírico e visível feito de rostos e nomes, cheiros, barulhos e sensações, perde em apelo, sentido e efetividade.

Não se pode deixar de reconhecer que a incursão de Das na filosofia de Wittgenstein é uma tentativa de sistematizar um conhecimento - o da etnografia do antropólogo, do cientista social - que sem este esforço está sempre sob ameaça de cair no lugar comum da intuição e da experiência interna, isto é, de algo que não pode ser compartilhado ou discutido e que, portanto, perde o status de conhecimento. Especialmente quando se fala na interface das Ciências Humanas com as Ciências Naturais, por exemplo, se trata da saúde. Seus trabalhos situam-se entre aqueles que identificam o empreendimento desta autora no confronto com discursos de verdade, encontrados, por exemplo, na medicina e na saúde pública, que fascinados pela tecnociência ou seduzidos pelo apelo econômico, deixam de lado os fatores sociais, políticos e experienciais que conferem à saúde o lugar de indicador e processo social (Kleinman e col., 1997).

Essas discussões encontram eco nos esforços empreendidos por autores no campo da saúde, que têm procurado no nosso meio desmistificar os modelos biomédicos criticando a racionalidade que suporta os discursos de verdade que fazem deste o modelo único (Luz, 2004), que se engajam na inclusão de temas como a violência na agência da saúde, como tem sido o caso de Minayo (2006), ou que entendem a ação do profissional e do pesquisador como engajada e comprometida com uma visão integral e transformadora da realidade (Spink, 2007). Tais esforços têm na obra de Veena Das elementos que contribuem para a discussão sobre o que, nas práticas de conhecimento e de intervenção, pode levar à crítica e à transformação da nossa realidade.

\section{Considerações Finais}

Das busca, por meio de seus trabalhos, um lugar de observação e de intervenção que a aproxima do que significa para uma mulher, indiana, habitar o mundo. No seu percurso de pesquisadora e ativista, ela encontra em situações de sofrimento social a presença de certas manifestações, atos e falas que configuram verdadeiras performances. Nestas, através de seus corpos, mulheres atuam para além da submissão que poderia ser entendida à primeira vista, registrando também a marca de uma resistência. Esse resistir aqui irá significar, de fato, um movimento que não é calculado, mas a manutenção da existência dos sujeitos no jogo social. Isso significa sair da invisibilidade através de ações que, ainda que condenáveis, ou, justamente por serem assim, colocam os sujeitos - neste caso, mulheres - numa posição ativa dentro do imaginário social, manejando aquilo de que a razão não pode dar conta. A experiência da sexualidade e da maternidade se institui, assim, através de um discurso que contém seus próprios corpos.

Eventos históricos e políticos como o Partition produzem um tremor no tecido social que, de um lado, 
torna mais visível a potência dos discursos que mantém o controle e a submissão da mulher, discursos predominantemente masculinos. Mas, por outro lado, estas situações limite deixam à mostra a presença de outras possibilidades, no mais das vezes encobertas, que podem oferecer um novo conhecimento, a reocupação e a incorporação da experiência do sofrimento.

Em meio à violência e ao sofrimento social, esta ação no cotidiano se faz sobre o imaginário, lá onde o conhecimento envenenado continua vivo. Em face do sofrimento, os sujeitos podem dar sentido àquilo que os atormenta e os coloca num outro lugar - social, familiar, subjetivo - não apenas através de narrativas que expliquem e dêem sentido àquelas experiências, mas também por ações que, como entendo, se fazem no âmbito de um imaginário mais imediato, mediado pelas relações afetivas e familiares nas quais os sujeitos estão engajados, utilizando de recursos que incluem linguagem e corpo no mesmo espaço de relações. O trabalho de resistência e de oposição aos discursos hegemônicos se faz, desta forma, de maneira muito mais sutil, sem o alarde dos manifestos e das passeatas, mas, também, nos usos que fazemos cotidianamente de nossos corpos.

Para desvendar esse processo, Veena Das promove o diálogo entre a argumentação foucaultiana sobre o confronto entre discursos na construção do conhecimento e a presença da linguagem no cotidiano como meio no qual se dá a instituição de possibilidades de vir a ser dos indivíduos e grupos, e empresta seu próprio corpo para sentir a dor do outro, apresentando, assim, uma dimensão para o trabalho do cientista social que extrapola, em muito, a melhor utilização de um recurso metodológico ou o perfeito entendimento de uma argumentação teórica.

Concluindo, entendo que as posições sobre a violência e a resistência feminina na perspectiva de Veena Das podem ser úteis para os estudos e intervenções no campo da saúde realizados com mulheres brasileiras de populações em situação de miséria crônica. Protagonistas em suas comunidades, jovens e adolescentes exercitam seus discursos sobre e com o corpo em contextos de sofrimento e exclusão social que podem ser comparados a experiências de um evento crítico (Carvalho, 2007). Escutar de mulheres jovens e pobres a respeito da maneira como (não) dirigem seus destinos e elaboram projetos de vida, buscando sua inser- ção em movimentos imaginários que se materializam em suas falas e nos usos e cuidados com seus corpos, aponta para a possibilidade de investigar fenômenos que remetem a esse mesmo cenário de submissão e resistência descrito por Das, podendo ser decisivo para, em contextos de promoção de saúde, dar sentido e intervir sobre processos que podem nos parecer sem sentido e sem razão, mas que guardam na sua incompletude e incerteza a marca indelével do humano.

\section{Referências}

BIEHL, J.; ESKEROD, T. Vita: life in a zone of social abandonment. Berkeley: University of California Press, 2005.

CARRETEIRO, T. C. Sofrimentos sociais em debate. Psicologia USP, São Paulo, v. 14, n. 3, p. 57-72, 2003.

CARVALHO, J. E. C. How can a child be a mother?: discourse on teenage pregnancy in a Brazilian favela. Culture, Health \& Sexuality, London, v. 9, n. 2, p. 109-120, 2007.

CAVELL, S. The claim of reason: Wittgenstein, skepticism, morality, and tragedy. Oxford: Oxford University Press, 1999.

DAS, V. Our work to cry: your work to listen. In: DAS, V. (Ed.). Mirrors of violence: communities, riots and survivors in South Asia. New Delhi: Oxford University Press, 1990. p. 345-398.

DAS, V. Voice as birth of culture. Ethnos, Abingdon, v. 6o, n. 3/4, p. 159-170, 1995.

DAS, V. Critical events: an anthropological perspective on contemporary India. New Delhi: Oxford University Press, 1996.

DAS, V. Language and body: transactions in the construction of pain. In: KLEINMAN, A.; DAS, V.; LOCK, M. (Ed.). Social suffering. Berkeley: University of California Press, 1997. p. 67-91

DAS, V. Wittgenstein and anthropology. Annual Review of Anthropology, Palo Alto, v. 27, p. 171-195, 1998.

DAS, V. The act of witnessing: violence, knowledge, and subjectivity. In: DAS, V. et al. (Org.). Violence and subjectivity. Berkeley: University of California Press, 200o. p. 205-225. 
DAS, V. Life and words: violence and the descent into the ordinary. Berkeley: University of California

Press, 2006.

GONÇALVES FILHO, J. M. Humilhação social: um problema político em psicologia. Psicologia USP, São

Paulo, v. 9, n. 2, p. 11-67, 1998.

HINTIKKA, M. B.; HINTIKKA, J. Investigating Wittgenstein. Oxford: Basil Blackwell, 1989.

KLEINMAN, A.; KLEINMAN, J. How bodies remember: social memory and bodily experience of criticism, resistance and delegitimation following China's Cultural Revolution. New Literary History, Baltimore, v. 25, n. 3, p. 707-723, 1994. 25th anniversary issue, part 1.

KLEINMAN, A.; DAS, V.; LOCK, M. (Org.). Social suffering. Berkeley: University of California Press, 1997.

KUSCH, M. Language as calculus vs. language as universal medium. Dordrecht: Kluwer Academic, 1989.
LUZ, M. Natural racional social: razão médica e racionalidade científica moderna. 2. ed. São Paulo: Hucitec, 2004.

MINAYO, M. C. S. The inclusion of violence in the health agenda: historical trajectory. Ciência e Saúde Coletiva, Rio de Janeiro, v. 11, n. 2, p. 375-383, 2006.

PETRYNA, A.; LAKOFF, A.; KLEINMAN, A. (Org.). Global pharmaceuticals: ethics, markets, practices. Durham: Duke University Press, 2006.

SAWAIA, B. O sofrimento ético-político como categoria de análise da dialética exclusão/inclusão. In: SAWAIA, B. (Org.). As artimanhas da exclusão: análise psicossocial e ética da desigualdade social. Petrópolis: Vozes, 1999. p. 97-118.

SPINK, M. J. P. Sobre a possibilidade de conciliação do ideal de integralidade nos cuidados à saúde e a cacofonia da demanda. Saúde e Sociedade, São Paulo, v. 16, n. 1, p. 18-27, jan./abr. 2007. 